\title{
COMPLEX MODEL OF MARKET PRICE DEVELOPMENT AND ITS SIMULATION
}

\author{
Bohumil STÁDNÍK ${ }^{1}$, Algita MIEČINSKIENĖ² \\ ${ }^{1}$ Faculty of Finance and Accounting, University of Economics in Prague, \\ nám. W. Churchilla 4, 13067, Prague, Czech Republic \\ ${ }^{2}$ Faculty of Business Management, Vilnius Gediminas Technical University, \\ Saulètekio al. 11, LT-10223 Vilnius, Lithuania \\ E-mails: ${ }^{1}$ bohumil.stadnik@email.cz; ${ }^{2}$ algita.miecinskiene@vgtu.lt (corresponding author) \\ Received 20 January 2015; accepted 21 July 2015
}

\begin{abstract}
The purpose of this study is to suggest a complex model of market price development for liquid assets, which is able to simulate all of the main features particular to the real price development and has a realistic financial explanation. First, the paper defines assumptions for the model construction from empirically observed processes. Then, the model is implemented in the real simulation environment. Finally, the ability of the model is checked to simulate empirically observed features, e.g. leptokurtic characteristics or skewness of the price distribution. Also, this paper newly defines and implements the resonance effect. FFT analysis is used to support oscillation processes. Finally, selected markets are provided with parameter optimisation of the model based on empirical observations. It was found that the model built under the previously mentioned assumptions was able to explain empirically observed effects that reversely support the correctness of those assumptions. The practical value of the constructed model can be found in many areas, including risk management and asset valuation.
\end{abstract}

Keywords: market price development, simulation, Matlab-Simulink price oscillations, volatility clustering, directional dependence, feedbacks, FFT, resonance, damped oscillations, forced oscillations.

JEL Classification: G1, G10.

\section{Introduction}

Many models of market price development exist, including independent random walk, memory models with a volatility or directional dependency. Henriksson and Merton (1981) developed the market-timing model. Anatolyev and Gerko (2005) proposed a market-timing test for conditional mean independence of financial returns. Huang and Wang (2010) researched the connection between liquidity and market crashes. Cernohorska et al. (2012) constructed a new market liquidity index based on the calculation of using traditional indicators of market depth, resiliency, tightness, volatility and liquidity for money, foreign exchange, bond and stock markets. Janda and Svárovská (2013) and Janda et al. (2014) investigated microfinance investment funds and found 
that in time, these funds provided modest but stable returns compared to benchmark market indices. Primbs and Rathinam (2009) modelled extraneous, value, momentum and hedge traders and explored the effects these trading strategies may have on price dynamics. Lux (2011) studied the causal relationship between the mood of investors and subsequent stock price changes. Price direction development dependence also takes place in the basic feedback process according to the behavioural finance concept, where the upward trend is more likely to be followed by another upward movement (Schiller 2003). This topic is also researched in other pieces of work, such as short-term trend trading strategy in futures market based on chart pattern recognition (Masteika et al. 2012) or the development of the conception of sustainable return investment decision strategy in capital and money markets (Rutkauskas et al. 2008). Larrain (1991) stated that long-term memory exists inside the financial market. Dealing with a similar topic, papers of Hsieh (1991), Peters $(1989,1991)$ focused mainly on the measurement of probability diversions from normality. Diviš and Teplý (2005) investigated the random walk hypothesis when testing the weak form of market efficiency in the Central European markets.

Despite the recent significant evolution in modelling of market price development, the complex model of financial market price behaviour is still missing. Therefore, we may argue that the following statement by Eugene F. Fama is still relevant: "First, until now most research has been concerned with simply finding statistical distributions that seem to coincide with the empirical distributions of price changes. There has been relatively little effort spent in exploring the more basic processes that give rise to the empirical distributions. In essence, there is as yet no general model of price formation in the stock market which explains price levels and distributions of price changes in terms of the behavior of more basic economic variables. Developing and testing such a model would contribute greatly toward establishing sound theoretical foundations in this area." (Fama 1965: 98-99).

The purpose of this study is to suggest a complex model of a market price development for liquid assets, which is able to simulate all the main features of the real price development and has a realistic financial explanation. In this research, we identify the realistic effects that must be involved in the model, as well as newly describe their mutual influence and their joint impact on the final development. In addition, we also suggest the financial interpretation of possible resonance effect and its implementation to the model. Finally, we also provide tests and calibration of the model parameters based on empirical observations of US stock market and European bond market in the period from 1963 to 2013. The constructed model is general and as such, it allows for the adjustment of parameters. Therefore, it can simulate a wide range of liquid financial markets. The practical value of the constructed model can be found in many areas, including risk management and asset valuation. The reason is that according to the Dynamical Systems Theory, it is more efficient to apply a general model based on an internal structure description than a black-box one. Based on direct empirical observations of a particular market, we can select only relevant processes for implementation from this general model; thus, the forecasting of financial market output becomes more 
precise. It also helps to answer such questions as what happens, if a certain internal process changes significantly. For example, in case economic news are not clustered, or traders start to use momentum trading or other technique, etc. Also, this model can predict a significance of resonance effect based on estimated resonance frequency and frequency of an external force. As the model is able to resolve into certain subsystems, it allows the calibration of each subsystem separately, which results into a more precise estimation of parameters for the whole system.

This paper logically follows a series of previous papers (Stádník 2013, 2014a, 2014b, 2014c), which covered the initial approach, description of financial market situations and its impact on volatility and price time series.

\section{Methodology of the research and system identification}

The methodology of the model construction is based on an identification of an internal structure and not only on a black-box description. Using the latter only works for datasets used for calibration and it cannot predict unusual situations.

The methodology can be divided into three main steps. The first step is to identify all of the realistic mechanisms, which influence the financial market price behaviour, define inputs and outputs of the system and possible memory mechanisms. The second step is to build the model: describe how the mechanisms mutually interact and how their joint impact on the output looks. The last step is to implement the model into the simulation environment and calibrate the model according to the empirical data. We decided to choose Matlab-Simulink environment for the implementation and Simulink Design Optimization tool for model parameter optimization.

Since we recognise more different markets worldwide and many different situations, the simulation environment should allow modelling all of them. After a model calibration, the simulation should provide outputs with characteristics comparable to the real financial data.

We consider the financial market as a dynamical system with certain inputs of the system, which causes appropriate output reaction. We also identify memory mechanisms. The input of the model covers (1) arrival of economic news and (2) participant orders, which include the use of trading techniques and other effects connected with behavioural finance.

Memory mechanisms:

- Clustering of economic news;

- Different up/down dynamics;

- Feedbacks without clustering (allows to model interest rates development);

- Feedbacks that cause clustering: clustering connected to jumps; clustering resulting from the use of different trading techniques (momentum and level trading).

Expected output of the model should cover:

- Leptokurtic distribution with empirically measured parameters;

- Volatility clustering; 
- Departures from normality;

- Departures from normality without clustering;

- Skewness;

- Jumps + oscillations;

- Ability to model slightly different output parameters connected to a specific financial market;

- Special effect involved in the model;

- Resonance.

According to the theory of dynamical systems, the dynamical system has a memory and the system output depends not only on the current input but also on all the history, which is stored in the memory - the state of the system.

\section{Model assembling}

Groups of agents. Based on empirical evidence we can state that groups of agents using the same trading technique at the same time are mutually independent in their activities. We can to filter them from the entire financial market system. For example, at each moment, we can separate a group of agents who use price level trading; or fundamental analysis, momentum trading or a certain tool of Technical Analysis. In the same way, we can separate agents who operate in different periods. The reaction to the incoming news is a special independent separable process.

Mutual connections of subsystems. We can state that during each period, a group of all orders incoming into the market is a mix of orders resulting from separable techniques. According to the financial market rule stating that there can be only one price at one moment on a particular market, we can conclude that each price step belongs to a certain match of a buy-and-sell order, each of which belongs to a different group of agents (If they are from the same group, they are usually not matched together in one moment). Thus, we can also resolve the final sequence of price steps into separable sequences of price steps depending on the rule we used to match the orders. If we integrate all the steps in a sequence, we obtain price development that belongs to this matching rule. The final price development is then the sum of more particular developments.

We distinguish two types of agents: agents placing market orders and agents placing limit orders. Market and limit orders have certain financial interpretation: traders using momentum trading, level trading, Technical Analysis or other technical tools usually place market orders as they must immediately react to the buying/selling signals that depend on feedback from the past development. On the other hand, fundamental investors usually accept a certain price range, and they usually accept waiting for a trade execution. Thus, we can state that the agents using techniques based on a certain buying/selling signal mostly prefer market orders but agents engaged in fundamental or independent actions (liquidity necessity traders or central bank interventions) mostly prefer limit orders.

As we also recognise agents who use a certain feedback technique to place market orders and fundamental traders who use limit orders. We decided to divide techniques into 
those that use feedback - "feedback orders" and to those that are independent of the historical development - "independent orders". If we, by way of example, matched orders resulting from momentum trading with "independent orders", we would obtain price development resulting from momentum trading. Analogically, if we matched orders from technical traders with "independent orders", we would obtain price development resulting from technical trading. The final price development is then the sum of separate developments resulting from different techniques. The principle is shown in Figure 1.

To obtain the development resulting only from a certain technique, we match incoming orders of that technique with independent orders, as shown in Figure 1. Equation (1) describes that a certain non-zero price step at time $t$ equals to one price step resulting from certain techniques while all other steps resulting from other techniques are zero.

$$
\begin{aligned}
& \Delta P(t)=\Delta P_{1}(t)+\Delta P_{2}(t)+\ldots+\Delta P_{n}(t) ; \Delta P=\sum_{i=1}^{n} \Delta P_{i}(t) ; \\
& \forall \Delta P_{i}>0 \Rightarrow \Delta P_{k}=0, k \neq i ; k, i \in\{1,2, \ldots, n\} .
\end{aligned}
$$

Equation (1) is used for the calculation of an overall output of the final simulation. It is built into the system, and it means that the output is resulting (based on superposition principle) from all the techniques we take into the consideration.

Equation (2) states that the total price at each moment of time is simply the sum of particular prices:

$$
P(t)=P_{1}(t)+P_{2}(t)+\ldots+P_{n}(t) ; \quad P=\sum_{i=1}^{n} P_{i}(t),
$$

where $P(t)$ is the resulting price and $P_{1}(t), P_{2}(t), \ldots P_{n}(t)$ are the prices resulting from matching orders of $n$ "feedback" techniques and an "independent" order.

Since rules for using different trading methods could be independent, we can state that all the subsystems are connected to the market price of an asset. For example, there is feedback from the output for those who use day level trading, momentum trading or other techniques. Also, incoming news can trigger the volatility clustering (resulting from level and momentum trading) or news valuation clustering. These mechanisms are described in detail further in the text. This way, assembling of the model includes connections and cooperation of the defining subsystems.

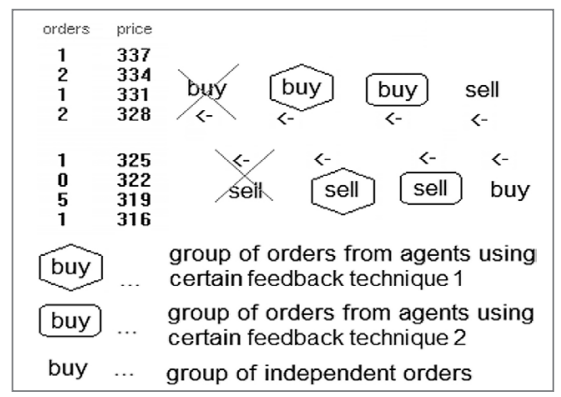

Fig. 1. Matching of orders from different techniques

Source: created by authors. 
Incoming economic news. The impact of economic news is considered a sequence of randomly distributed steps at time, which also have a randomly distributed size and sign. According to theories accepted worldwide, we also expect a certain clustering of economic news. This effect was already described by Mandelbrot (1963: 418): "Bad news is more likely followed by bad news and large changes tend to be followed by large changes, of either sign, and small changes tend to be followed by small changes." In addition, there is also a certain clustering mechanism connected to the incoming economic news, which was already mentioned by Fama (1970). It states that important information cannot be evaluated completely and immediately. This clustering mechanism could be connected to observed departures from normality.

According to empirical evidence, we recognize certain jump reaction in the case of one unexpected piece of news, as shown in Figure 2a. The jump is characterised by a very low related trading activity.

We may draw a conclusion that market price development, with respect to the arrival of economic news, includes more significant crashes than significant jumps, and much less minor negative changes than positive ones. This feature is a kind of memory or feedback mechanism as we recognise up or down direction, which predicts the future dynamics. Such evidence can be represented by time series of jumps, which can be seen in Figure $3 \mathrm{a}$, where we consider the independent distribution of economic news.

Adjusted input is illustrated in the Figure $3 \mathrm{~b}$ with considered news clustering.

Appropriate subsystem implementation using Matlab-Simulink is depicted in Figure 4. The implementation involves variable parameters, which enables us to simulate more types of economic news impacts, their frequency and possible random adjustment of each type.

By way of example, we can consider three different types of reaction in our current implementation (Fig. 4) with respect to the average size of a step: short, long and mid-size. The shortest one has the highest arrival frequency and, analogically, the longest one has

a)

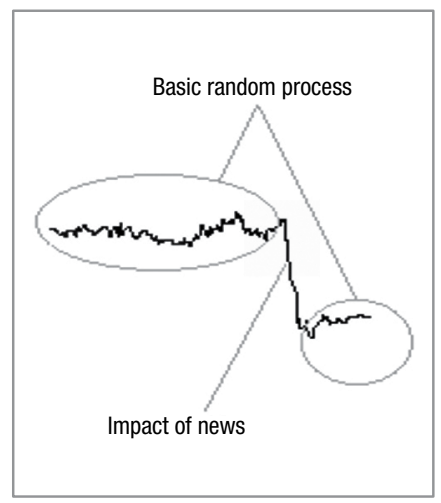

b)

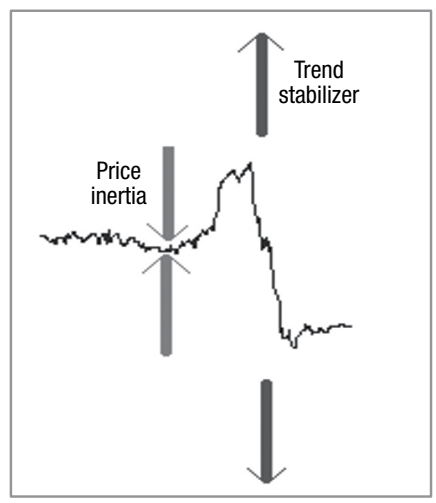

Fig. 2. Impact of important economic news (a), price inertia, trend stabiliser feedback impact (b) Source: created by authors. 
the lowest incoming frequency. Each average size is adjusted using normally distributed increments with the mean equal to the average size of a step. Adjustable parameters in the simulation environment allow optimising them for more types of financial markets.

We use uniform number generator, which generates a number from a uniform distribution, to generate the sequence of jumps. The output sequence in Figure 4 is the signal from "Scope 6" in Figure 4. "Scope 1" in Figure 4 represents the integrated sequence of jumps.

a)

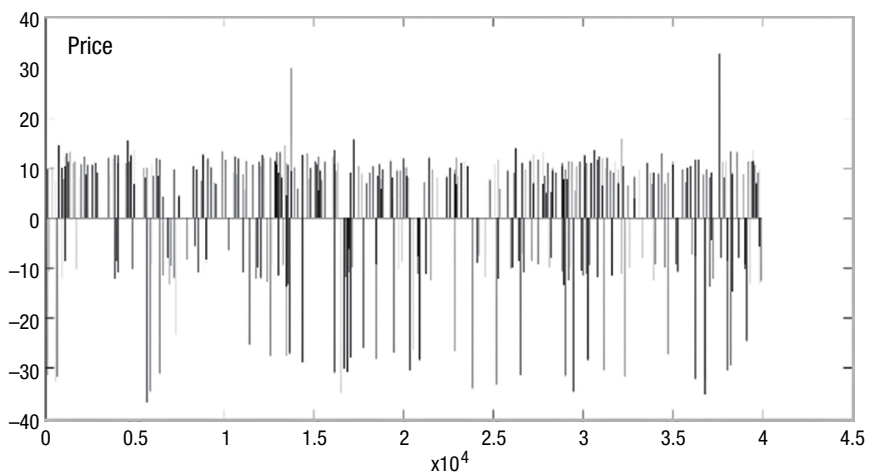

b)

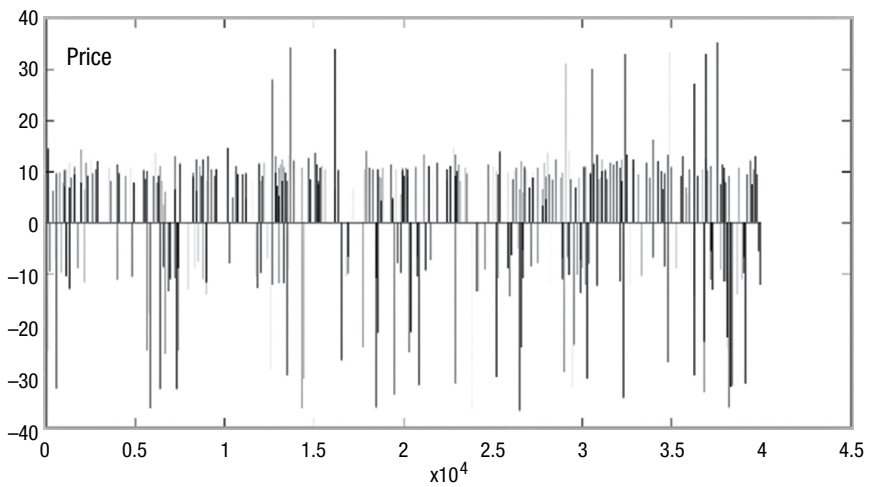

Fig. 3. Independent economic news impact (a), clustering (b)
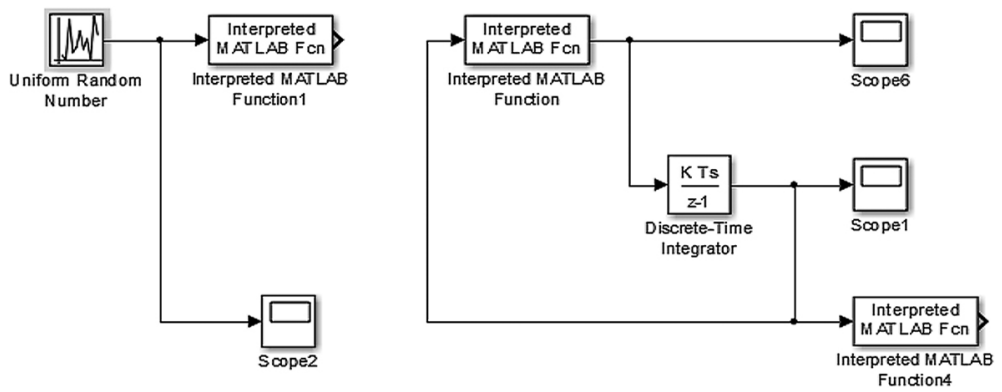

Fig. 4. Economic news subsystem 
Participant orders. Participant orders are responsible for the primary random process, which results from the book of orders. This process generates the independent random process in the case of independent arrival of bid and offer orders. There is an example of a uniformly distributed sequence of minimum price steps in Figure 5a.

Successive price changes constitute independent random walk (Fig. 5b). In the case of feedback, we also simulate the departures from normality, which are connected to the directional dependency. A more detailed explanation of the idea of feedback is provided by Stádník (2014c).

Within financial markets, we recognise two most important types of feedback - price inertia and trend stabiliser (Fig. 2b).

The price inertia feedback is pushing the market price back to a certain level. In this context, a certain level means, for example, the price level set after the last economic news of high importance (level trading). Trend stabiliser feedback keeps the movement in a certain direction (momentum trading).

Feedback without clustering. Influence of feedback could be divided into two main impacts. The first is a non-clustering impact and the second - a clustering impact. This idea is discussed in more detail by Stádník (2014 b) and also tested in Stádník (2012). A non-clustering impact is illustrated in the Figures $6 \mathrm{a}$ and $6 \mathrm{~b}$. Such mechanism, for example, may enable us to simulate mean reversion interest rates development.

a)

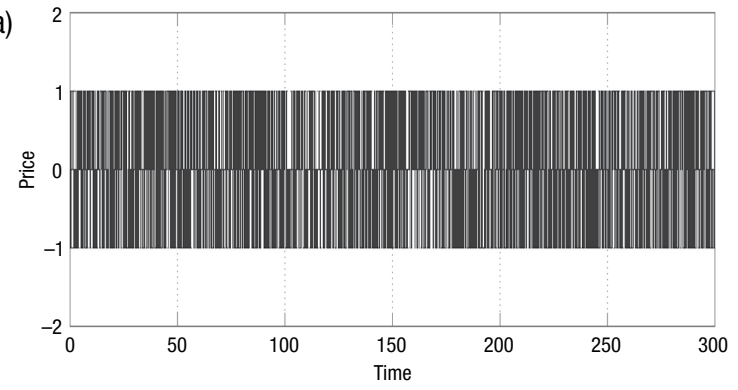

b)

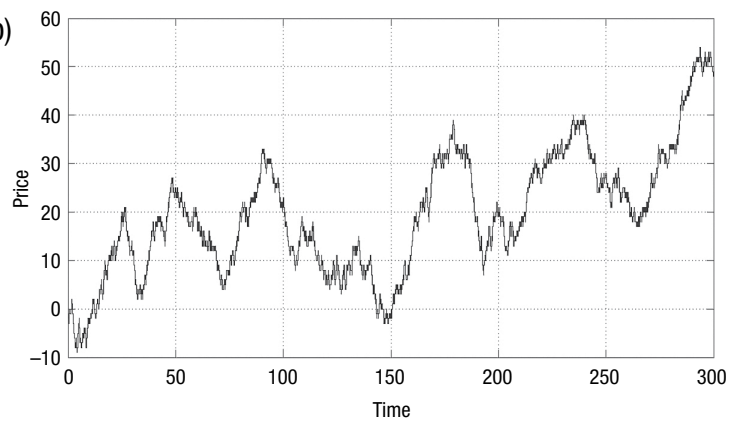

Fig. 5. Series of independent steps (simulated path 3) (a), Primary RW, independent (simulated path 3) (b) 
Price inertia can work separately and it can be responsible for the departures from normality without clustering. Leptokurtic features in the distribution are compared to a development without feedback in Figures $7 \mathrm{a}$ and $7 \mathrm{~b}$.

Figure 8 provides the sequence of price steps where we use economic news together with price inertia feedback and economic news clustering.

a)

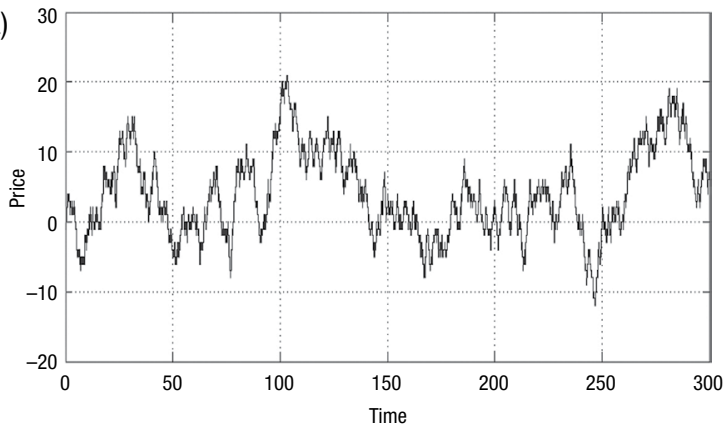

b)

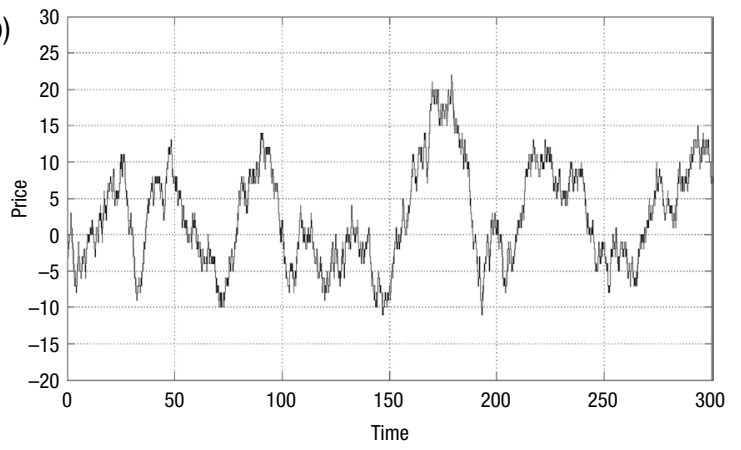

Fig. 6. Primary RW+ price inertia (simulated path 1) (a), Primary RW + price inertia (simulated path 3 )

a)

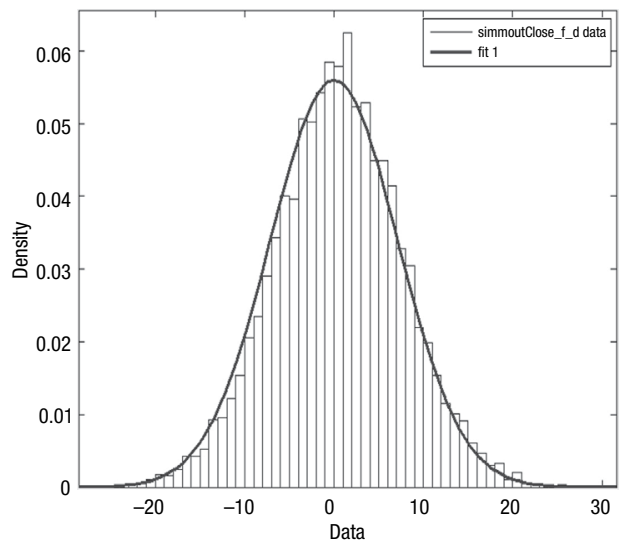

b)

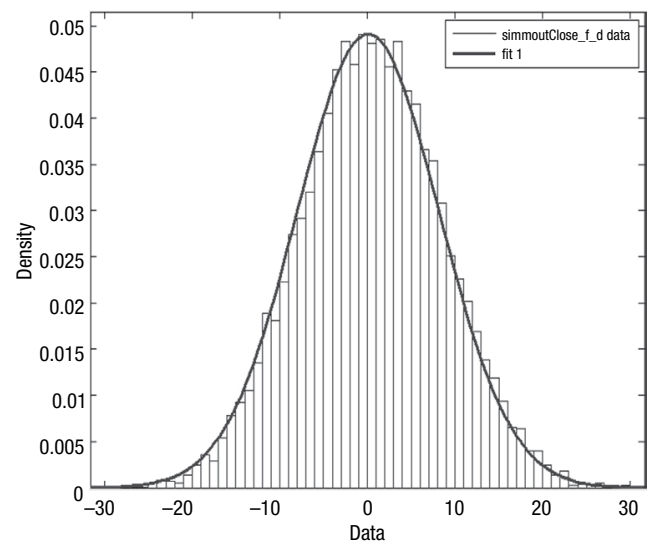

Fig. 7. Primary RW with a price inertia feedback (a) and without feedback (b) 


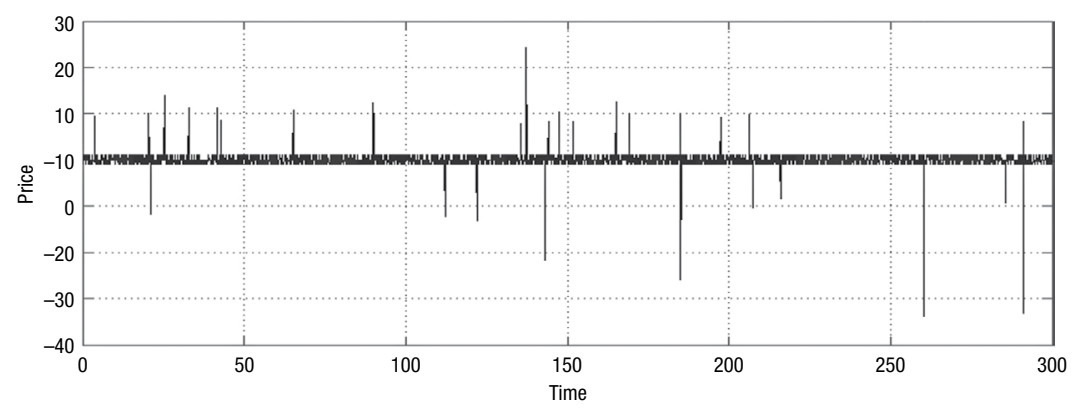

Fig. 8. Input: economic news + price inertia kurtosis + news clustering (simulated path 1)

The feedback mechanism that causes clustering. One possible financial interpretation of the volatility clustering is connected to clustering of news. However, there must also be a certain other mechanism, which is responsible for clustering. We observe this mechanism inside a very short time series (Figs. 9a, 9b) as well as inside the periods without incoming economic news. Thus, it cannot be connected only to the clustering of news or news evaluation.

Volatility clusters in empirical data series are usually described by a certain type of a volatility dependency. One of the models that use volatility dependency is the Gaussian Mixture, which also has an acceptable financial interpretation: financial market may stay in two regimes with changing high and low volatility.

Application of the Markov law of motion to the Gaussian Mixture leads to the Markov Regime Switching Model (Baum, Petrie 1966). We may find many extensions of this model such as introduced by Krolzig (1997), etc. Probably the most famous contributions in the area of volatility description were made by Engle (1995) and Bollerslev (1986) - ARCH and GARCH processes. New research in this area was done by Roch (2011) or Witzany (2013). ARCH, GARCH and other volatility models provide a statistical description of volatility clusters in financial data series. Unfortunately, they do not explain clustering from the financial point of view.

a)

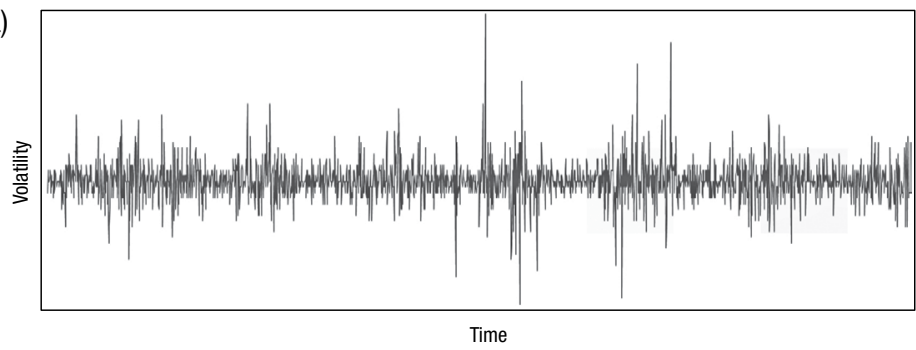

b)

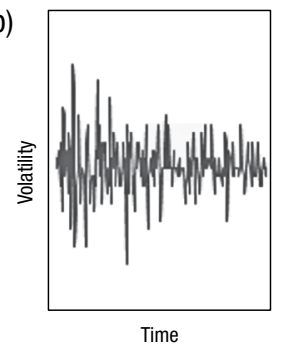

Fig. 9. Example of the sequence of damped oscillations in 5-minutes volatility series of EUR/USD (a), detailed (b) 
The realistic financial explanation of observed clusters with popular theories is very difficult. We may state that probably the simplest ideas explaining the volatility clustering are connected to market changes between periods of high and low activity (Chordia et al. 2001), which are caused by clustering of important economic news inside the periods of higher and lower economic uncertainty. Unfortunately, these effects cannot explain volatility clusters in the periods with no observable incoming economic news or in very short periods. As stated by Cont (2005), other explanations, such as the competition of more trading strategies, do not allow confirming mechanisms being responsible for volatility clustering.

One realistic explanation is provided by Stádník (2014a) and is based on the assumption that clustering is considered to be a sequence of damped oscillations with random disturbances. Oscillations could be caused by a cooperation of forces resulting from momentum and level trading techniques. This research is also supported by momentum studies of Pesaran and Timmermann (1995), Chan et al. (1996), Stankevičienė and Gembickaja (2012), Donefer (2010), Easley et al. (2011, 2012); Franck et al. (2013), Rey and Schmid (2007), Witzany (2009), Žd'árek (2012).

The basic description of damped oscillation movements is given by equation (3). The particular solution of equation (3) is expected to be in the form of an exponential function of time, and it may lead to an oscillation process. The analogy in finance is as follows: the left side of the equation represents the acceleration of the price change at time $t ; y$ is the deflection from the initial value and constant $c_{1}$ represents the trend stabiliser; constant $c_{2}$ represents the damping and $c_{3}$ is connected to the price inertia feedback. In this case, we presume the cooperation of momentum and price inertia feedback without any random disturbances, which will be built later to this research.

$$
c_{1} \frac{d^{2} y}{d t^{2}}+c_{2} \frac{d y}{d t}+c_{3} y=0
$$

Matlab-Simulink implementation of equation (3) to the subsystem is provided in Figure 10 .

There is a possible output of the subsystem in Figure 11a.

The sequence of oscillations triggered by the incoming economic news is depicted in Figure 11b. News arrive at a random time, and its initial impact (initial deflection from the equilibrium state $y$ ) is random as well. This idea is connected to the research made by Fama (1970) about evaluation of economic news. The second effect causing clustering is described by momentum and level trading cooperation (Stádník 2014a).

FFT analysis. We are trying to find a certain support regarding activities of certain techniques that result in periodical oscillations. For this purpose, we can use Fourier transformation (equation 4) of financial signal for vectors of length N. We check different investment instruments and a wide range of the periods in the research.

$$
X(k)=\sum_{j=1}^{N} x(j) \omega_{N}^{(j-1)(k-1)}, \text { where } \omega_{N}=e^{(-2 \pi i) / N} .
$$




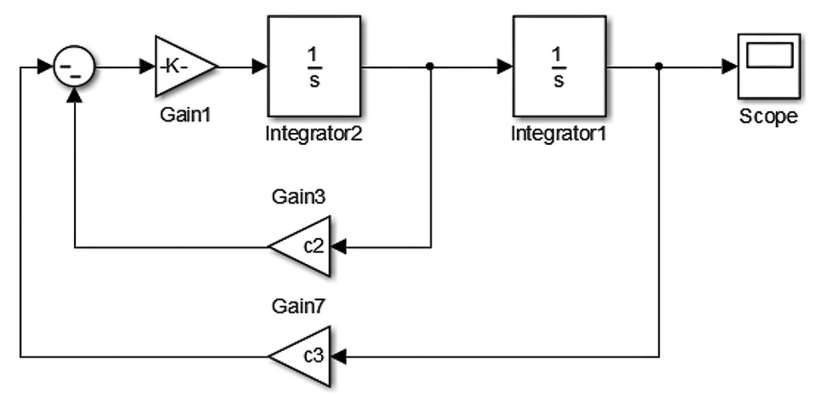

Fig. 10. Subsystem of oscillations

a)

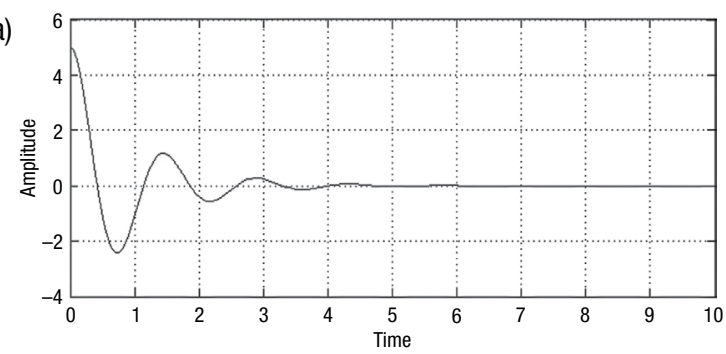

b)

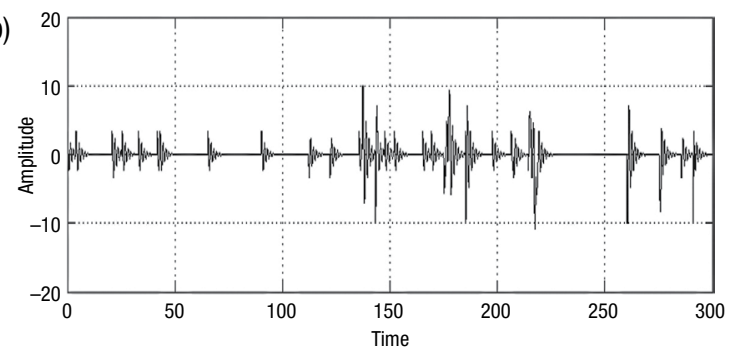

Fig. 11. Primary oscillation (simulated path 1), oscillations with random disturbances (simulated path 1)

$X$ and $x$ are transform and inverse transform pair given for vectors of length $N$, and $i$ is the imaginary unit. We use Matlab function $Y=f f t(x)$, which returns the discrete Fourier transform (DFT) of the vector $x$, computed with a fast Fourier transform (FFT) algorithm.

Based on comparison with a spectrum of white noise (Fig. 12a) from a spectral analysis, we can suspect the existence of oscillation in the development. Visually, we cannot recognise significant peaks in the spectrums (Fig. 12b, 13a, 13b) but we can recognise certain areas of higher significances in the lower frequencies.

From the complex point of view, we also make spectrograms (Fig. 14a, 15a, 16a). A spectrogram is a visual representation of the spectrum of frequencies at a time (Fig. 14b, $15 b, 16 b)$. 
a)

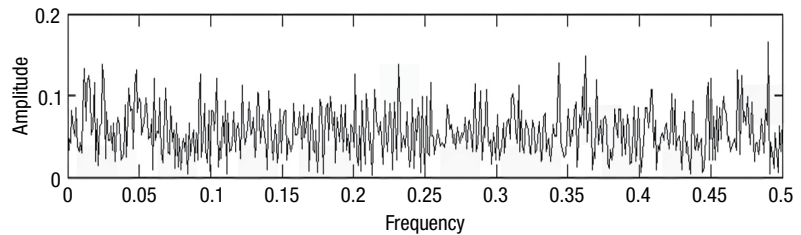

b)

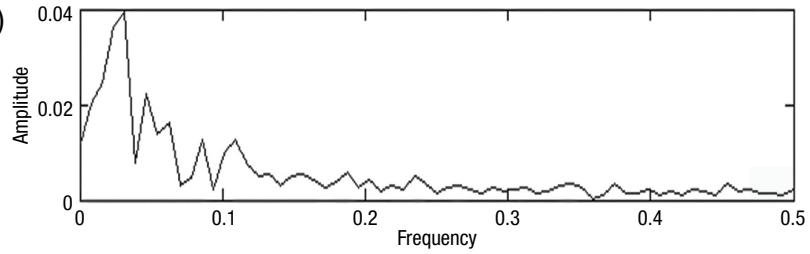

Fig. 12. Gaussian noise spectrum (a), Bund 1 minute - price series spectrum (b)

a)

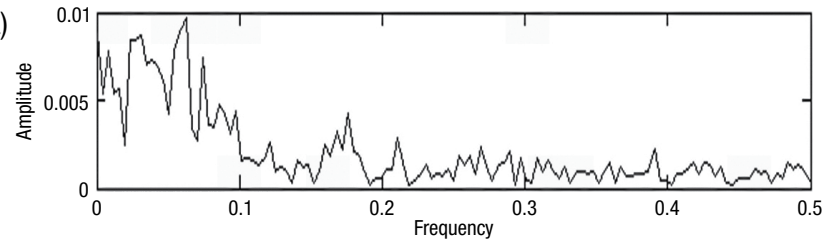

b)

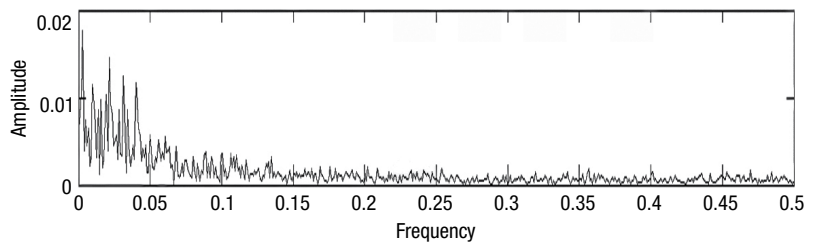

Fig. 13. Bund Futures 5 minutes - price series (a), Bund Futures 1 day - price series (b)
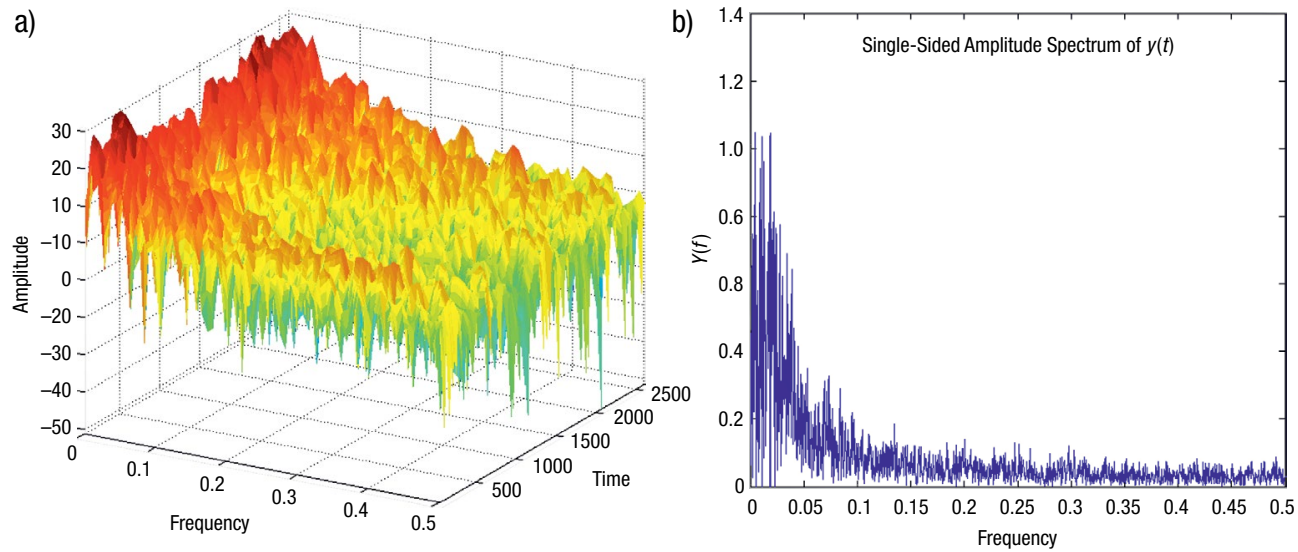

Fig. 14. The Boeing Company (BA) - 1 day price series, spectrogram (a), spectrum (b) 

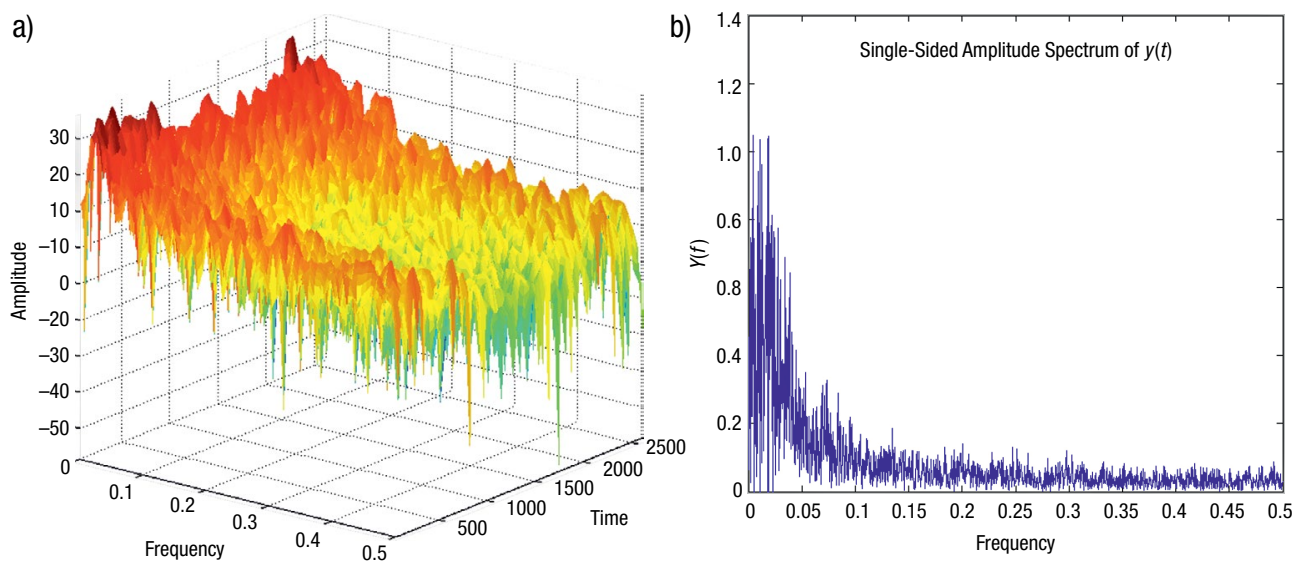

Fig. 15. International Business Machines Corporation (IBM) - 1 day price series spectrogram (a), spectrum (b)
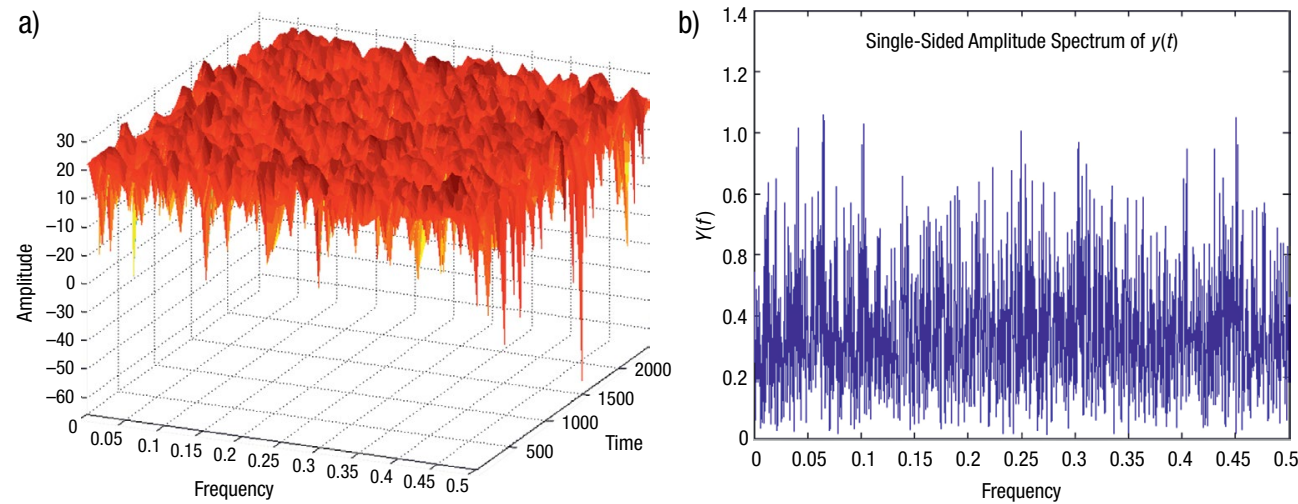

Fig. 16. White noise spectrogram (a), spectrum (b)

According to the comparison of real market developments (Figs 14, 15) to the case of 3 sinus waves (Fig. 17) and the white noise spectrogram (Figs 16a, 16b), we can conclude that this effect for the real market is much less significant than in the case of a signal consisting of pure sine waves only, but of the higher significance than in the case of white noise.

In Figure 18, there is also a spectrogram for bond futures based on periods of one and five minutes. We can state that the spectrograms have the same features for all the periods (comparing one day development spectrograms in Figures 14a, 14b and a high frequency series in Figures 18a, 18b) and for the wide range of investment instruments.

All these results also support the price oscillations for higher frequencies, which could be very well explained for example by a cooperation of a momentum and level trading. Special effects - resonance. An interpretation of the resonance effect is a certain external periodic force, which is able to force an ongoing oscillation. For example, in finance, 
it is periodically incoming economic information in the moment of oscillations caused by a cooperation of momentum and level trading. The basic formula is (5), where the right side of the equation represents external force, $\Omega$ is an angle velocity of an external force and $a$ is its amplitude. The left side is the same as in the equation (3).

$$
c_{1} \frac{d^{2} y}{d t^{2}}+c_{2} \frac{d y}{d t}+c_{3} y=a \sin \Omega t .
$$

The solution of the equation (5) may lead to a significant growth in the amplitude when $\Omega$ equals the resonance frequency.

The entire system is adjusted by random disturbances to better resemble the reality. The example of simulated market price development containing resonance is presented in Figure $19 \mathrm{~b}$ and without resonance - in Figure 19a.

Study of the resonance effect is an interesting topic for possible further research.

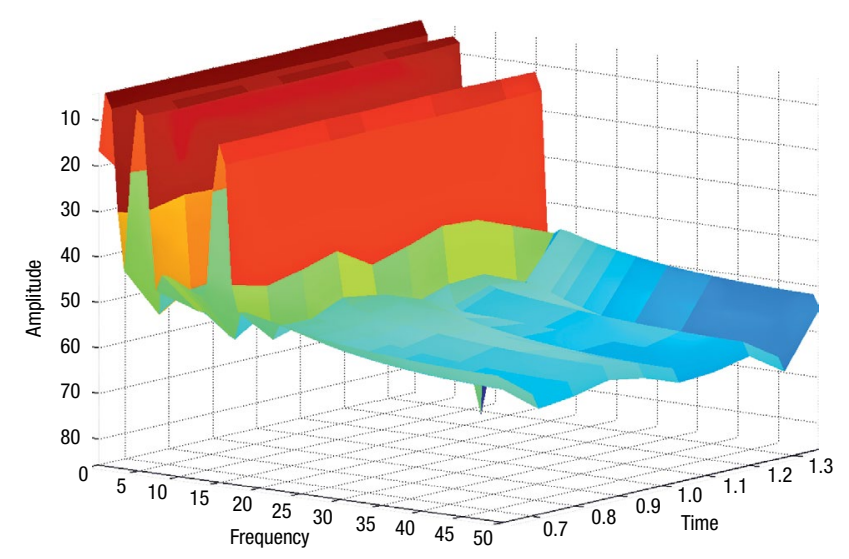

Fig. 17. Sum of 3 sinuses (a), Signal Processing Toolbox
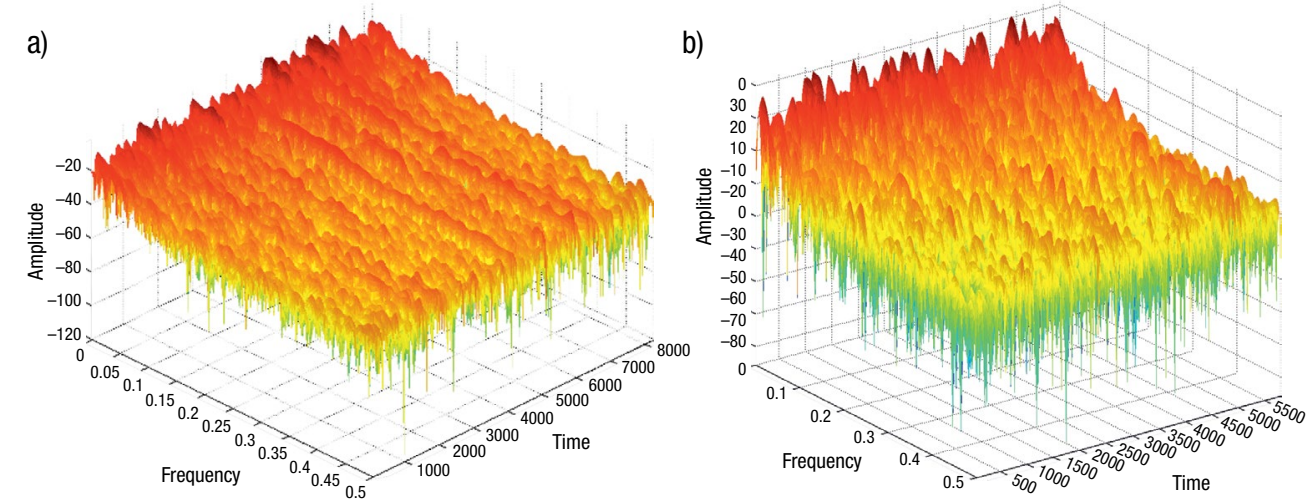

Fig. 18. Bund Futures $1 \mathrm{~min}$ - price series spectrogram (a), $5 \mathrm{~min}$ - price series spectrogram (b), Signal Processing Toolbox 
a)

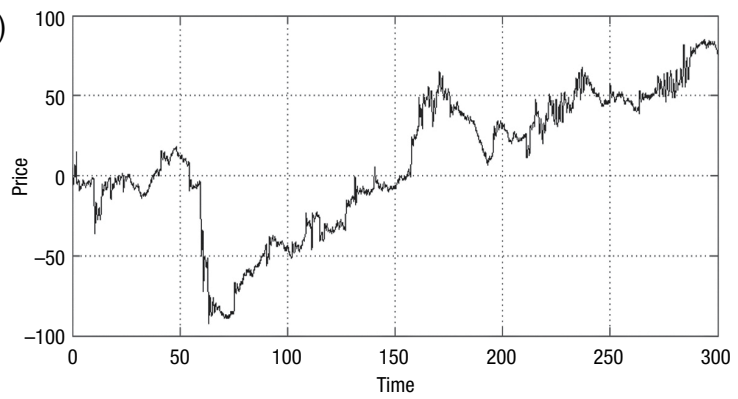

b)

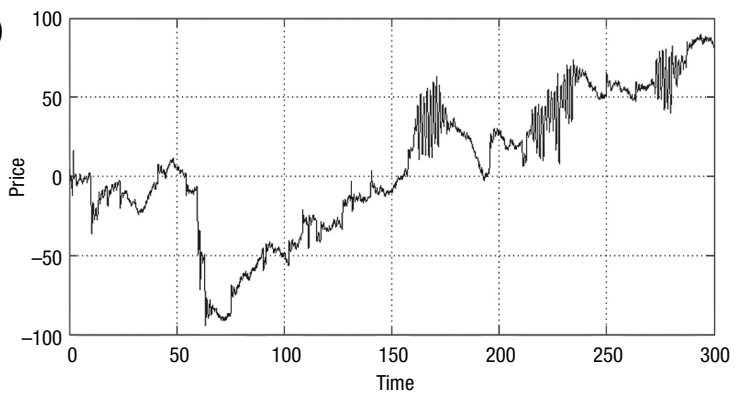

Fig. 19. Simulated path without resonance (a), simulated path with the resonance effect (b)

\section{Complex model and its empirical tests}

The complex model is designed to involve all mentioned subsystems.

The resulting Matlab-Simulink implementation is presented in Figure 20. The final output (Scope 2 in Figure 20), which represents a market price development, contains steps from independent participants, steps from those using price inertia feedback ("feedback from output" in the figure), steps resulting from volatility clustering due to momentum and level trading ("oscillations subsystem" in the figure), jumps from incoming economic news ("news subsystem" in the figure) and steps resulting from volatility clustering due to news evaluation ("oscillations subsystem" in Figure 20, triggered by incoming economic news). The system also allows us to consider the resonance effect ("external force subsystems" in the figure). All of them participate in the mix of steps, which is integrated in the output of the system. Blocks denoted as "Interpreted Matlab Fcn" contain implemented Matlab algorithms, which adjust the input of the block according to required rules. For example, based on an output of "Uniform Random Number", there is a certain type of value of an information jump in the output of block A in Figure 20.

Simulation is in the discrete time intervals and it allows us to generate more steps inside the interval.

The model is general and all the simulations should lead to a high statistical accordance with the empirical data. In the research, we provide detailed model parameter optimisation for the US stocks index S\&P500 (Figs 21a, 21b) and European Bond markets represented by Eurex futures FGBL (Fig. 23a). We carry out optimisation on daily de- 
velopments and daily price/yield distributions. We use Simulink Design Optimization tool, which provides interactive tools, functions, and Simulink blocks for estimating and tuning Simulink model parameters using numerical optimisation. The parameters of simulated distributions, such as kurtosis or skewness and the level of clustering (measured by GARCH) in volatility data series (one possible simulated path is in Fig. 24), are very close to the empirical ones. In Figure $22 \mathrm{a}$, there is an example of resulting development (path 1) compounded from subsystems development in Figures 6, 8, 11 (path 1). The parameters of daily price distribution or level of clustering should be the same as in Figure 21a. Also, other resulting developments (Figs 22b, 24) are compounded from the subsystem outputs.

There is an illustrative example of simulated market price distribution in Figure $23 \mathrm{~b}$. This simulated distribution has almost the same statistical features as the real development in Figure 23a (kurtosis, level of clustering, skewness, extreme values, etc.).

There is an example of volatility clusters on the simulated way 3 in Figure 24.

Here, we do not provide solution to the market efficiency problem. However, according to the existing price development connected to the feedback system, created due to agents using price dependency techniques, we do not think that the economic information is "fully reflected" (Fama 1970) and, thus, the financial market described in the model cannot be efficient. In other words, agents using their techniques influence the price development and do not take into consideration the fair price valuation of an asset.

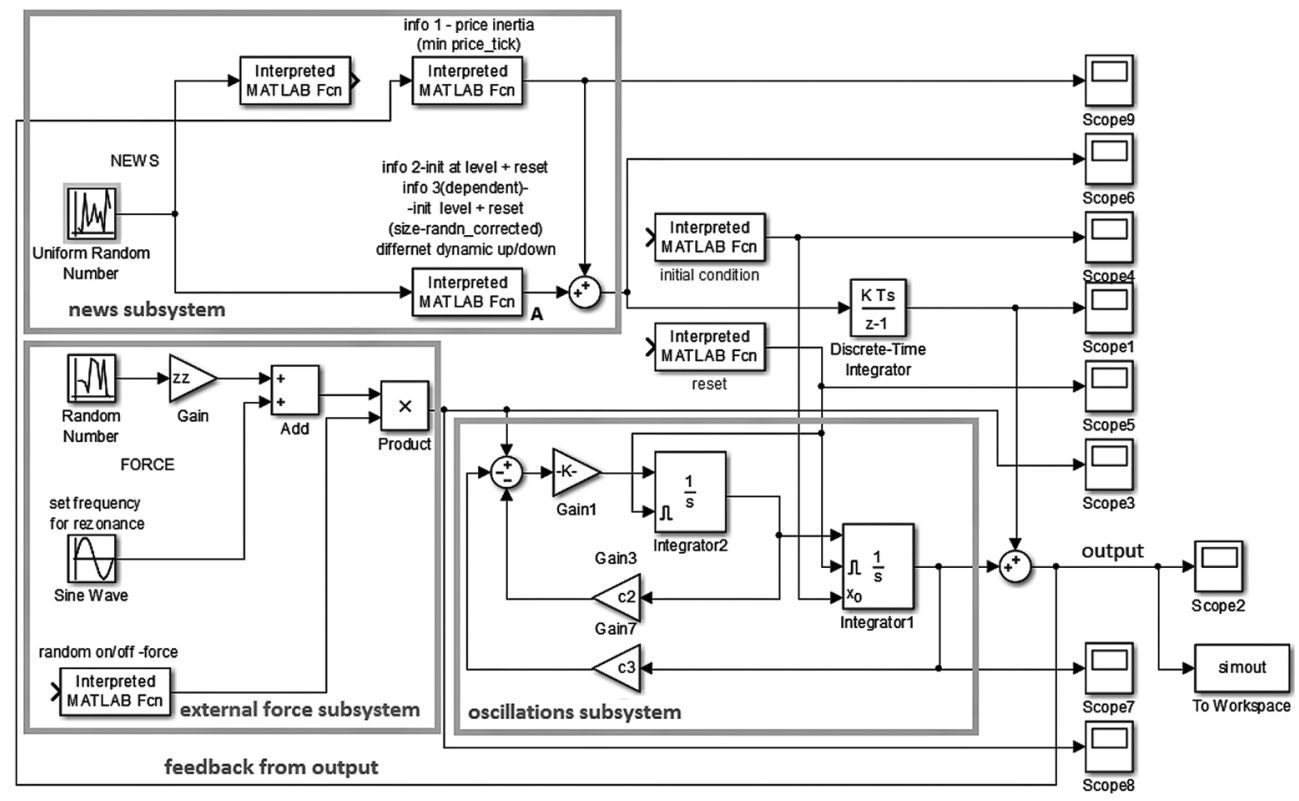

Fig. 20. The entire system, input: economic news, order activities, feedback, skewed, news clustering 
a)
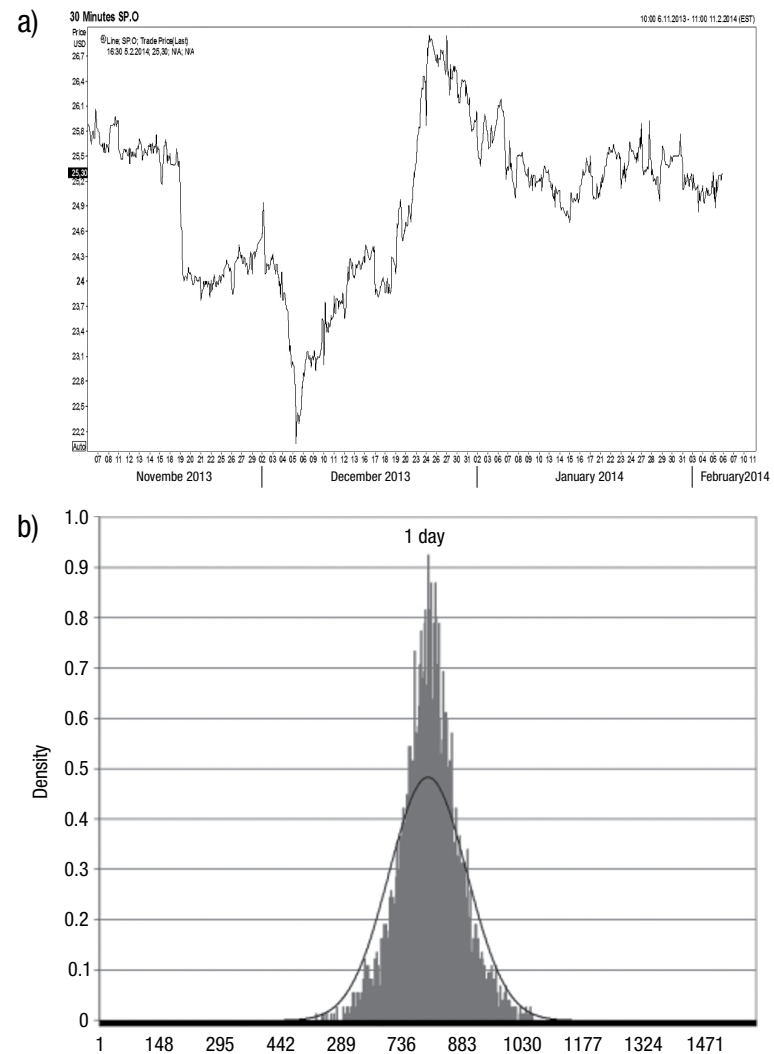

Fig. 21. Real development S\&P500 (2014) (a) and the daily price distribution (1963-2013) (b)

a)

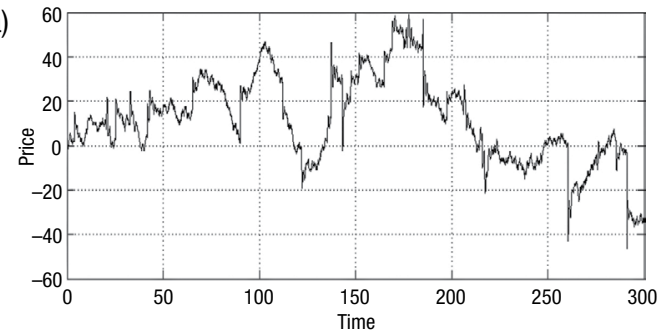

b)

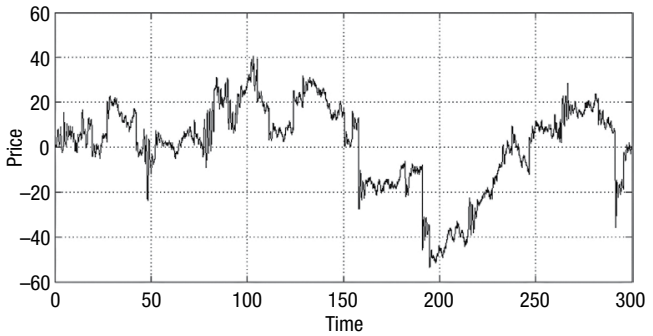

Fig. 22. Price development - simulated path 1 (a), price development - simulated path 2 (b) 
a)

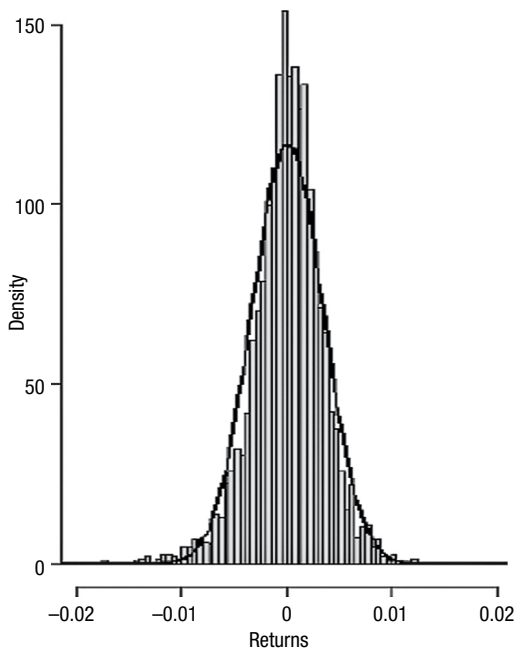

b)

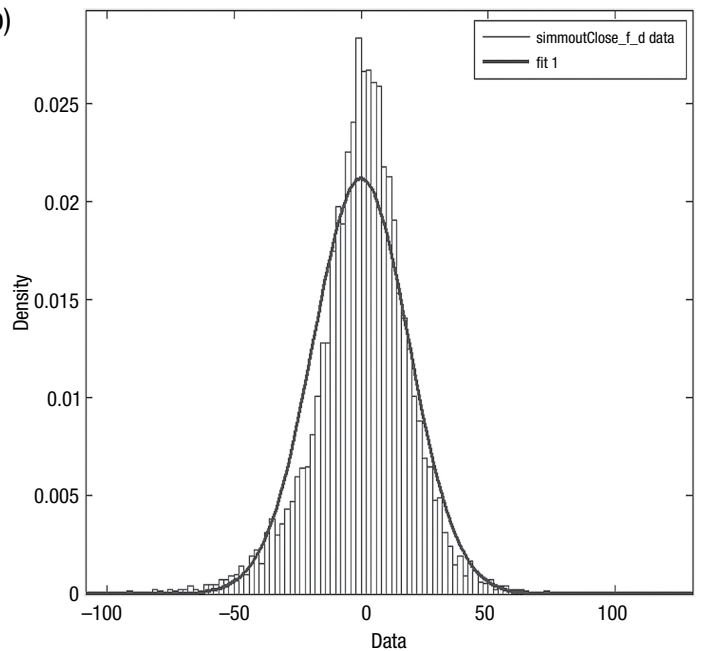

Fig. 23. Real distributions (1990-2004) (a) and statistically very close simulated distributionwith mean 0.0058 , std. 18.7915, kurtosis 5.3880, skewness 0.4141

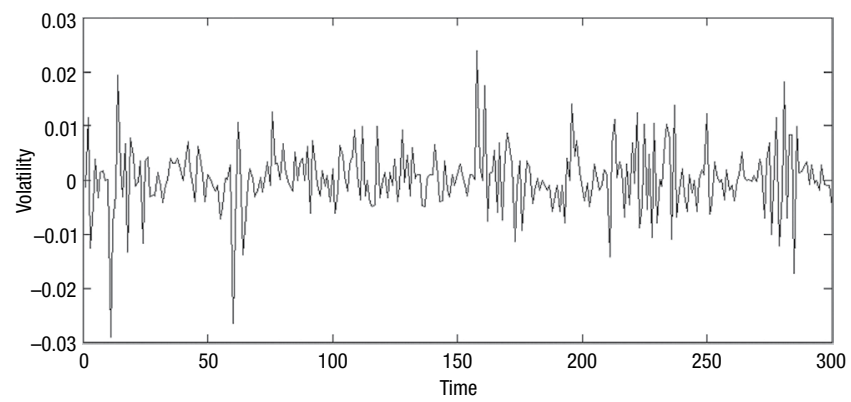

Fig. 24. Clustering on path 3 (volatility data series)

\section{Conclusions}

In this paper, we suggest a complex model of a market price development of liquid assets and provide its implementation in the real simulation environment. The model simulates all main features of the real price development and it has realistic financial explanation. We defined assumptions for the design of the entire model from various processes, which we empirically observed. We also defined their mutual influence and joint impact on the final development. We found that the model built following the previously mentioned assumptions explains empirically observed effects, which reversely supports the correctness of those assumptions.

In this research, we identified and quantified the realistic effects influencing the price behaviour and newly described the resonance effect. We implemented it in the MatlabSimulink simulation environment and check whether the model is able to simulate empirically observed features of the market price development, e.g. leptokurtosis, skewness 
or extreme values, or simulate volatility clusters. We found that the model simulates all these properties accurately. Our simulations led to highly statistically significant accordance with the empirical data. In addition, we also made tests based on FFT analysis in order to support oscillation processes that are important for modelling of volatility clusters.

This general model is suitable for a wide range of liquid financial instruments such as stocks, bonds, currencies or futures and it works both on daily time periods and high frequency time periods.

\section{Limitations and Possibilities for Future Research}

We would also like to mention possible limitations of the presented paper. We only implement methods and techniques previously described in scientific papers and mentioned in the Introduction. Therefore, general price manipulations and other secret methods, which may be used by algorithmic trading, are certainly not covered here. Another limitation is the research of resonance that could be distinctly upgraded. However, we think that we created a foundation, which could be further developed.

As for possibilities for future research, we recommend making parameter optimisation for a certain investment instrument, period or a specific financial market. The model has a solid general theoretical background, which is open to the addition of a new subsystem. Thus, we recommend constructing processes, which could be newly observed within financial markets. For example, there is a possibility of building a new trading technique resulting from the progress of algorithmic trading.

\section{Acknowledgements}

The research was supported by the institutional grant VŠE IP 100040 (Ministry of Education of the Czech Republic).

\section{References}

Anatolyev, S.; Gerko, A. 2005. A trading approach to testing for predictability, Journal of Business and Economic Statistics 23: 455-461. http://dx.doi.org/10.1198/073500104000000640

Baum, L. E.; Petrie, T. 1966. Statistical inference for probabilistic functions of finite state Markov chains, The Annals of Mathematical Statistics 37(6): 1554-1563.

http://dx.doi.org/10.1214/aoms/1177699147

Bollerslev, T. 1986. Generalized autoregressive conditional heteroskedasticity, Journal of Econometrics 31: 307-327. http://dx.doi.org/10.1016/0304-4076(86)90063-1

Chan, L. K. C.; Jegadeesh, N.; Lakonishok, J. 1996. Momentum strategies, Journal of Finance 51(5): 1681-1713. http://dx.doi.org/10.1111/j.1540-6261.1996.tb05222.x

Chordia, T.; Roll, R.; Subrahmanyam, A. 2001. Market liquidity and trading activity, The Journal of Finance 56(2): 501-530. http://dx.doi.org/10.1111/0022-1082.00335

Cernohorska, L.; Teply, P.; Vrabel, M. 2012. The VT index as an indicator of market liquidity risk in Slovakia, Journal of Economics 60(3): 223-238. 
Cont, R. 2005. Volatility clustering in financial markets: empirical facts and agent-based models, in G. Teyssiere, A. Kirman (Eds.). Long memory in economics. Berlin, Heidelberg: SpringerVerlag, 289-309 http://dx.doi.org/10.2139/ssrn.1411462

Diviš, K.; Teplý, P. 2005. Information efficiency of Central Europe stock exchanges, Czech Journal of Finance 9-10: 471-482.

Donefer, B. S. 2010. Algos gone wild: risk in the world of automated trading strategies, The Journal of Trading 5: 31-34. http://dx.doi.org/10.3905/JOT.2010.5.2.031

Easley, D.; De Prado, M. L.; O’Hara, M. 2011. The microstructure of the flash crash: flow toxicity, liquidity crashes and the probability of informed trading, Journal of Portfolio Management 37(2): 118-128. http://dx.doi.org/10.3905/jpm.2012.39.1.019

Easley, D.; De Prado, M. L.; O’Hara, M. 2012. The volume clock: insights into the high-frequency paradigm, Journal of Portfolio Management 39(1): 19-29.

Engle, R. F. 1995. ARCH: selected readings. Oxford, UK: Oxford University Press.

Fama, E. 1965. The behavior of stock market prices, The Journal of Business 38(1): 34-105.

Fama, E. 1970. Efficient capital markets: a review of theory and empirical work, The Journal of Finance 25(2): 383-417. http://dx.doi.org/10.2307/2325486

Franck, A.; Walter, A.; Witt, J. F. 2013. Momentum strategies of German mutual funds, Financial Markets and Portfolio Management 27(3): 307-332.

http://dx.doi.org/10.1007/s11408-013-0211-z

Henriksson, R. D.; Merton, R. C. 1981. On the market timing and investment performance of managed portfolios II - statistical procedures for evaluating forecasting skills, Journal of Business 54(4): 513-533. http://dx.doi.org/10.1086/296144

Hsieh, D. A. 1991. Chaos and nonlinear dynamics: application to financial markets, Journal of Finance 46: 1839-1877. http://dx.doi.org/10.1111/j.1540-6261.1991.tb04646.x

Huang, J.; Wang, J. 2010. Liquidity and market crashes, Review of Financial Studies 22(7): 2607-2643. http://dx.doi.org/10.1093/rfs/hhn086

Janda, K; Svárovská, B. 2013. Performance of microfinance investment vehicles, Journal of Economics 61(1): 47-66.

Janda, K.; Rausser, G.; Svarovska, B. 2014. Can investment in microfinance funds improve riskreturn characteristics of a portfolio?, Technological and Economic Development of Economy 20(4): 673-695. http://dx.doi.org/10.3846/20294913.2014.869514

Krolzig, H. M. 1997. International business cycles: regime shifts in the stochastic process of economic growth, Applied Economics Discussion Paper 194. University of Oxford.

Larrain, M. 1991. Testing chaos and nonlinearities in T-bills rates, Financial Analysts Journal 47(5): 51-62. http://dx.doi.org/10.2469/faj.v47.n5.51

Lux, T. 2011. Sentiment dynamics and stock returns: the case of the German stock market, Empirical Economics 41(3): 663-679. http://dx.doi.org/10.1007/s00181-010-0397-0

Mandelbrot, B. 1963. The variation of certain speculative prices, The Journal of Business 36(4): 394-419. http://dx.doi.org/10.1086/294632

Masteika, S.; Rutkauskas, A. V.; Alexander, J. A. 2012. Continuous futures data series for back testing and technical analysis, International Proceedings of Economics Development and Research 29: 265-269.

Pesaran, M. H.; Timmermann, A. 1995. Predictability of stock returns: robustness and economic significance, Journal of Finance 50: 1201-1228.

http://dx.doi.org/10.1111/j.1540-6261.1995.tb04055.x

Peters, E. 1989. Fractal structure in the capital markets, Financial Analysts Journal 45(4): 32-37. http://dx.doi.org/10.2469/faj.v45.n4.32 
Peters, E. 1991. Chaos and order in the capital markets: a new view of cycles, prices, and market volatility. New York: John Wiley \& Sons.

Primbs, J. A.; Rathinam, M. 2009. Trader behavior and its effect on asset price dynamics, Applied Mathematical Finance 16(2): 151-181. http://dx.doi.org/10.1080/13504860802583444

Rey, D. M.; Schmid, M. M. 2007. Feasible momentum strategies: evidence from the Swiss stock market, Financial Markets and Portfolio Management 21(3): 325-352.

http://dx.doi.org/10.1007/s11408-007-0051-9

Rutkauskas, A. V.; Miečinskienè, A.; Stasytytė, V. 2008. Investment decisions modelling along sustainable development concept on financial markets, Technological and Economic Development Economy 14(3): 417-427. http://dx.doi.org/10.3846/1392-8619.2008.14.417-427

Roch, A. F. 2011. Liquidity risk, price impacts and the replication problem, Finance and Stochastics 15(3): 399-419. http://dx.doi.org/10.1007/s00780-011-0156-X

Schiller, R. J. 2003. From efficient market theory to behavioural finance, Journal of Economic Perspectives 17(1): 83-104. http://dx.doi.org/10.1257/089533003321164967

Stádník, B. 2012. Testing of market price direction dependence on US stock market, Journal of Business, Management and Education 10(2): 205-219. http://doi.dx.org/10.3846/bme.2012.15

Stádník, B. 2013. Market price forecasting and profitability - how to tame random walk?, Business: Theory and Practice 14(2): 166-176. http://doi.dx.org/10.3846/btp.2013.18

Stádník, B. 2014a. Spring oscillations within financial markets, Procedia-Social and Behavioral Sciences 110(24): 1176-1184. http://dx.doi.org/10.1016/j.sbspro.2013.12.964

Stádník, B. 2014b. The riddle of volatility clusters, Business: Theory and Practice 15(2): 140148. http://doi.dx.org/10.3846/btp.2014.14 2014

Stádník, B. 2014c. The puzzle of financial market distributions, Journal of Economics, Ekonomický Časopis 7: 709-728.

Stankevičienè, J.; Gembickaja, N. 2012. Market behavior: case studies of NASDAQ OMX Baltic, Journal of Business, Management and Education 10(1): 110-127.

Witzany, J. 2013. Estimating correlated jumps and stochastic volatilities, Prague Economic Papers 2: 251-283. http://dx.doi.org/10.18267/j.pep.451

Witzany, J. 2009. Valuation of convexity related derivatives, Prague Economic Papers 18(4): 309-326. http://dx.doi.org/10.18267/j.pep.356

Žd'árek, V. 2012. An empirical investigation of the purchasing power parity hypothesis in European transition countries, Prague Economic Papers 17(2): 257-276.

http://dx.doi.org/10.18267/j.pep.423

Bohumil STÁDNíK, PhD in Finance (University of Economics in Prague), is Assistant professor at the Department of Banking and Insurance of the University of Economics in Prague (Czech Republic). His research interests are financial engineering, modelling of financial dynamical processes, market price development and forecasting, theory and practice of fixed income securities.

Algita MIEČINSKIENĖ, PhD in Economics (Vilnius Gediminas Technical University), is an Associate Professor at the Department of Finance Engineering at Vilnius Gediminas Technical University (Lithuania). Her research interests are effective pricing, foreign direct investment (greenfield investment, mergers and acquisitions), multinational corporate economics and finance, and finance engineering. 